\title{
DIVUSI INOVASI DAN BUDAYA: PENGGUNAAN BATEE RANUP DALAM TRADISI $M E U-U R O H$ (STUDI KASUS DI DESA COT LAGAN KECAMATAN WOYLA KABUPATEN ACEH BARAT)
}

\author{
Rahma Hidayati, Reni Juliani, Nidar \\ Program Studi Ilmu Komunikasi,Universitas Teuku Umar \\ Email: rahmahidayati@utu.ac.id
}

\begin{abstract}
ABSTRAK
Aceh is a region rich in tradition. One of the traditions that continues to be practiced is the meandering tradition. But in practice this tradition has undergone innovation. The ancient traditions were carried out by bringing a meaningful message that has a high meaning and now this tradition is carried out by bringing a "betel tree" print invitation. This happened to Cot Lagan community of Woyla Subdistrict of Aceh Barat District, so there was a cultural shift in the mega-uroh tradition. The purpose of this study is to know the cause of the cultural shift. This research uses qualitative method with data collection technique through interview and documentation. The results of the study show that the shift in cultural use of batee ranup in the tradition of meu-uroh is caused by the lack of understanding and love of the people about the culture so it is very easy to accept the new culture that enters and develops among them. This shift in culture is also due to the rapid development of technology that has brought many changes in the life of the community, including in terms of culture. The development of this technology brings betel arts to the middle of the community as an invitation and gradually replaces the batee ranup position in the meu-uroh tradition. In addition, the use of betel arts invitations is also considered as cheaper and more practical in comparison to using the batee ranup.

Keywords: Innovasion, Cultural, Batee Ranup, Meu-uroh.
\end{abstract}

\section{A. PENDAHULUAN}

Budaya sebagai warisan yang bersifat turun temurun dari generasi ke generasi sudah sepatutnya terus ada dan dilestarikan. Namun, budaya akan menghilang ketika suatu generasi melupakan tradisi tersebut. Pada akhirnya, budaya tersebut akan menghilang dan tradisi yang telah ada sebelumnya akan menjadi bagian dari sejarah budaya suatu tempat atau wilayah.

Budaya di Indonesia dari sabang sampai merauke mempunyai ciri khas tersendiri. Begitu juga Aceh, salah satu provinsi yang ada di Indonesia yang merupakan daerah multikultural, multi-etnik, agama, ras dan golongan. Selain terkenal dengan kekayaan alam dan pahlawan nasionalnya, Aceh juga merupakan wilayah yang kaya dengan adat dan budayanya. Di antara sekian banyak budaya yang terus lestari, ada budaya dan adat-adat tertentu yang sudah mulai hilang dari tengah-tengah masyarakat. Hal ini merupakan dampak dari globalisasi yang menyebabkan terjadinya inovasi yang mengakibatkan adanya pergeseran budaya antara budaya tradisional dengan modern, sehingga tanpa kita sadari adat istiadat kita yang luhur sedikit demi sedikit berganti dengan budaya modern yang lebih kekinian.

Puteh (2012:106) menyatakan bahwa perubahan budaya merupakan suatu gejala umum di dalam setiap masyarakat yang terjadi sepanjang masa. Hal tersebut dikarenakan timbulnya perubahan 
lingkungan masyarakat dan adanya pengaruh dari budaya lain. Begitu pula perubahan budaya Aceh dikarenakan pengaruh dari luar dan globalisasi yang terus terjadi.

Masyarakat Aceh khususnya masyarakat yang ada di Aceh Barat memiliki budaya yang khas, dimana sirih menjadi simbol budayanya. Bagi masyarakat Aceh Barat, sirih bukan hanya sekedar tumbuhan yang memiliki khasiat untuk kesehatan. Tetapi lebih dari pada itu, sirih menjadi simbol budaya yang memiliki banyak makna. Salah satu maknanya adalah simbol penyambung silaturrahmi atau dalam bahasa aceh dikenal dengan istilah meu-uroh (mengundang). Meu-uroh adalah kegiatan bertamu ke rumah kerabat dengan membawa batee ranup yang dilakukan oleh orang yang hendak melaksanakan hajatan dengan maksud memberitahukan atau mengundangnya untuk datang ke hajatan tersebut.

Batee ranup meruapakan wadah sirih yang biasanya terbuat dari emas, perak, tembaga, nikel atau tempurung (Dadek, 2014:176). Batee Ranup yang dibawa ketika ingin mengundang sebuah hajatan adalah sebagai pembuka kata sebelum menyampaikan maksud yang sesungguhnya. Oleh karena itu, Batee Ranup ini juga merupakan simbol (komunikasi non-verbal) yang mendukung komunikasi verbal yang akan dilakukan.

Budaya meu-uroh dengan batee ranup ini dianut oleh semua masyarakat Aceh Barat khususnya masyarakat di pedesaan. Salah satu desa yang pernah menganut budaya tersebut adalah Desa Cot Lagan di Kecamatan Woyla. Namun, saat ini budaya meu-uroh dengan batee ranup ini mulai memudar. Masyarakat kini ketika hendak melaksanakan hajatan, tidak lagi menggunakan batee ranup sebagai bagian dari budaya meu-uroh. Mereka hanya melakukan tradisi tersebut dengan komunikasi verbal tanpa komunikasi non-verbal sebagai pendukungnya, seperti mengundang langsung. Bahkan, ada segelintir orang yang hanya mengirimkan lembaran undangan melalui perantara orang lain.

Kehadiran lembar-lembar undangan tersebut terkait dengan muncul dan berkembangnya teknologi informasi dan komunikasi di tengah masyarakat, seperti adanya televisi di setiap rumah yang pada akhirnya membuat masyarakat terpengaruh dan mengikuti berbagai hal yang mereka lihat di televisi tersebut. Hal ini didukung pula oleh alat-alat teknologi yang telah merambah ke perdesaan. Selain itu kehadiran teknologi menjadi sarana untuk mewujudkan perubahan masyarakat desa yang sebelumnya identik dengan hal-hal tradisional dan mempertahankan identitas kebudayaan mereka menjadi lebih modern dan mengikuti arus perkembangan zaman.

Namun beda halnya ketika peneliti melakukan observasi awal. Pada saat peneliti menanyai 5 orang masyarakat Desa Cot Lagan Kecamatan Woyla Kabupaten Aceh Barat mengenai tradisi meuuroh dengan batee ranup yang kini telah tergantikan dengan lembaran undangan yang lebih modern. Hasilnya, 2 orang masyarakat cenderung menganggap remeh undangan yang berupa selembar kertas, terlebih jika lembaran undangan tersebut datang melalui perantara orang lain. Sedangkan 3 orang lainnya menganggap meu-uroh dengan batee ranup sudah kuno dan merepotkan jika dibandingkan dengan undangan berupa selembar kertas yang lebih modern. 
Kegiatan me-uroh dengan batee ranup atau dengan undangan berupa selembar kertas samasama bertujuan untuk memberitahukan tentang hajatan yang akan digelar. Perbedaannya adalah meuuroh dengan batee ranup dapat mempererat tali silaturrahmi, dimana kegiatan ini dilakukan dengan intensitas waktu yang lebih lama jika dibandingkan meu-uroh dengan mengantar atau mengirimkan selembar undangan.

Sudah seharusnya budaya yang dapat menyambung silaturrahmi seperti ini dilestarikan. Namun, jika pada akhirnya budaya tersebut hilang tentu ada penyebab yang mendorongnya, salah satunya adalah kemajuan teknologi yang drastis di tengah masyarakat.

Berdasarkan uraian latar belakang yang telah dikemukakan di atas, penelitian ini bertujuan untuk mengetahui penyebab terjadinya pergeseran budaya penggunaan batee ranup dalam tradisi meu-uroh di tengah-tengah masyarakat di Desa Cot Lagan Kecamatan Woyla Kabupaten Aceh Barat.

\section{B. TINJAUAN PUSTAKA}

\section{Budaya}

Dalam bahasa Sangsekerta, Kata "budaya" disebut "buddhayah" jamak dari kata "buddhi" bermakna budi atau akal. Sedangkan dalam bahasa Latin disebut "colore" yang bermakna sebagai daya dan kegiatan manusia mengolah dan mengubah alam (Soekanto, 2007:234).

Menurut Sanderson (2011:44), ada empat karakteristik kebudayaan, yaitu:

a. Kebudayaan mendasarkan diri kepada sejumlah simbol. Simbol sangat penting dalam kebudayaan karena merupakan transmisi informasi yang membentuk sebuah kebudayaan.

b. Kebudayaan itu dipelajari dan tidak terikat pada pewarisan budaya tersebut.

c. Kebudayaan adalah sistem yang menjadi tanggung jawab bersama oleh para anggota suatu masyarakat

d. Kebudayaan cenderung terintegrasi. Kebudayaan penyatuan dari berbagai macam komponen di dalam masyarakat yang menyatu walaupun terdapat konflik, friksi dan kontradiksi yang juga ada.

Selain memiliki karakteristik, Koentjaraningrat menambahkan bahwa kebudayaan juga memiliki wujud (Nurudin, 2014:50), yaitu:

a. Wujud sebagai suatu kompleks gagasan, konsep dan pikiran manusia;

b. Wujud sebagai suatu kompleks aktivitas;

c. Wujud sebagai benda.

\section{Komunikasi Non Verbal}

Menurut Sobur (2009: 122), Komunikasi non-verbal merupakan cara yang dilakukan untuk menyampaikan suatu informasi tanpa menggunakan verbal bahasa, maka tanda non-verbal berarti 
tanda minus bahasa atau tanda minus kata. Jadi, dapat dikatakan bahwa tanda non-verbal diartikan semua tanda bukan kata-kata.

\section{Batee Ranup}

Batee ranup (puan) merupakan wadah untuk meletakkan sirih yang terbuat dari perak dengan teknik tuangan ke dalam cetakan, kemudian disepuh dengan emas. Bentuk Batee ranup seperti setengah bola (lingkaran). Di sisi luar dihiasi dengan ukiran motif suluran dan lekuk-lekuk. Selain itu batee ranup ini menjadi simbol keindahan budi pekerti dan akhlak yang luhur. Wadah tersebut sebagai satu kesatuan perwakilan sifat keadatan. Batee ranup ini biasa digunakan sebagai tempat sirih sehari-hari atau menjemput tamu (meu-uroh) (acehutara.go.id). selain batee ranup, ranup (sirih) itu sendiri memiliki berbagai makna antara lain (kebudayaan.kemdikbud.go.id):

\footnotetext{
a. Ranup sebagai simbol pemuliaan tamu.

b. Ranup sebagai simbol perdamaian dan kehangatan sosial.

c. Ranup sebagai media komunikasi sosial.
}

Batee ranup adalah bentuk komunikasi non-verbal yang berfungsi untuk mendukung komunikasi verbal yang dilakukan. Batee ranup merupakan sebuah simbol yang memiliki makna tersendiri bagi sekelompok masyarakat yang menggunakannya.

\section{Meu-uroh}

Meu-uroh adalah tradisi yang ada di Aceh, yang memiliki makna "menjemput tamu". Meuuroh adalah kegiatan berkunjung ke rumah kerabat atau kenalan ketika hendak melaksanakan hajatan, dengan maksud memberitahukan berita tersebut kepada kerabat agar datang ke hajatan yang akan dilaksanakan itu.

Meu-uroh biasanya dilakukan dengan membawa batee ranup sebagai pembuka kata sebelum menyampaikan maksud yang sesungguhnya. Fungsi ranup atau sirih salah satunya adalah untuk meuuroh. Dalam hubungan sosial, ranup berperan sebagai sarana memuliakan tamu (penghormatan kepada tamu) sekaligus untuk membangun hubungan harmonis dan solid antarkelompok. Selain itu ranup juga dianggap sebagai simbol kemuliaan (pemulia jamee), penenang dalam menyatukan pendapat (sapeu kheun ngon buet), dan penyambung silaturrahmi sesama (meu-uroh), serta simbol kerendahan hati dan pemberani dalam masyarakat (acehutara.go.id).

\section{Teori Difusi Inovasi}

Teori Difusi inovasi diperkenalkan oleh Everett M Rogers. Teori ini menjelaskan bagaimana proses suatu inovasi disampaikan (dikomunikasikan) melalui saluran-saluran tertentu dengan jangkan waktu tertentu yang terjadi antara anggota-anggota dari suatu sistem sosial (Prastyanti, 2013:59).

Dapat disimpulkan bahwa sebuah inovasi akan diterima ataupun tidak oleh seorang individu atau anggota masyarakat dan proses tersebut dalam rentan waktu tertentu. Akan terjadi perbedaan waktu bagi individu dan masyarakat yang satu dengan lainnya dalam menerima ataupun menolak sebuah inovasi sehingga kita tidak dapat memastikan jangka waktu yang dibutuhkan individu dan 
masyarakat untuk menerima ataupun menolak suatu inovasi. Oldenberg dan Glanz menjelaskan bahwa perbedaan waktu tersebut disebabkan oleh beberapa faktor diantaranya kebutuhan target adopter atau kesesuaian inovasi dengan kebutuhan, kendala untuk mengadopsi, sikap dan perilaku,dan lain-lain. Perbedaan tersebut juga yang membagikan individu dan masyarakat dalam beberapa karakteristik yaitu Innovators, Early Adopters (Perintis/Pelopor), Early Majority (Pengikut Dini), Late Majority (Pengikut Akhir), dan Laggards (Kelompok Kolot/Tradisional) (Prastyanti, 2013:59-60).

\section{METODOLOGI PENELITIAN}

Dalam penelitian ini, penulis menggunakan pendekatan kualitatif. Menurut Sugiyono (2009:15) penelitian ini berlandaskan pada filsafat postpositivisme, digunakan untuk meneliti pada kondisi objek yang alamiah dimana peneliti adalah sebagai instrumen kunci, pengambilan sampel sumber data dilakukan secara purposive, teknik pengumpulan data dengan triangulasi, analisis data bersifat induktif/kualitatif, dan hasil penelitian kualitatif lebih menekankan makna daripada generalisasi.

Objek penelitian ini adalah tradisi meu-uroh dengan batee ranup di Desa Cot Lagan Kecamatan Woyla Kabupaten Aceh Barat. Penulis sengaja memilih penelitian di desa ini karena berkaitan dengan yang penulis dapatkan bahwa telah terjadi pergeseran budaya komunikasi nonverbal batee ranup dalam tradisi meu-uroh di Desa Cot Lagan Kecamatan Woyla Kabupaten Aceh Barat tersebut. Penelitian ini menggunakan teknik wawancara dengan mewawancarai 8 informan. 1 orang informan merupakan Ketua Majelis Adat, 1 orang informan merupakan Keuchik Desa Cot Cot Lagan Kecamatan Woyla Kabupaten Aceh Barat dan 6 orang informan lainnya merupakan masyarakat Desa Cot Cot Lagan Kecamatan Woyla Kabupaten Aceh Barat. Tekni pengumpulan data lainnya dengan teknik dokumentasi yaitu mengumpulkan referensi dari berbagai sumber.

\section{HASIL PENELITIAN}

\section{Sejarah dan Makna Batee Ranup}

Setiap daerah memiliki budaya dan tradisi yang telah lama dianut dan senantiasa diwariskan dari generasi ke generasi. Seperti batee ranup yang telah menjadi bagian dari budaya aceh dari berabad-abad yang lalu. Hal tersebut senada dengan yang disampaikan oleh Ketua MAA Aceh Barat kepada peneliti, beliau menuturkan

"Batee ranup ini asli punya kita yang diwariskan oleh nenek moyang dari jaman dulu. Jika ada yang bilang batee ranup ini punya orang india, mungkin ada benarnya karena di aceh dulu banyak di huni oleh orang-orang luar termasuk india. Tapi makna dari batee ranup itu sendiri telah disesuaikan dengan kehidupan masyarakat aceh yang memegang syariat islam. Jadi nggak sama dengan yang digunakan oleh orang hindu india." (Wawancara, 22 Maret 2018) 
Adapun makna dari batee ranup ini sendiri adalah kemuliaan atau simbol penghormatan untuk orang yang hendak diundang oleh si empunya hajatan. Hal ini berdasarkan yang disampaikan oleh Keuchik Desa Cot Lagan, beliau mengungkapkan

"That dhit makna batee ranup nyoe. Makna jieh simbol peumulia ureueng yang keuneuk ta undang. Dilei mandum pakek cara meu-uroh nyoe, tapi watee ka mulai meu-ubah na masa jieh adat nyoe Cuma dipakek untuk undang ureueng-ureueng tertentu mantong lagai blah tuan, gure beut, ulama-ulama yang na lam daerah nyan dan ureueng-ureueng tuha gampong. Batee ranup ini memiliki makna yang luhur yakni memuliakan atau kemuliaan bagi orang yang hendak diundang. Dulu semua orang di desa cot lagan ini menggunakan cara meu-uroh tersebut, namun ketika tradisi ini mulai mengalami perubahan ada masa di mana tradisi ini tetap dilakukan sesuai dengan yang semestinya meskipun hanya ketika mengundang orangorang tertentu saja seperti keluarga mertua dari pembuat hajatan, guru-guru di pesantren, ulama-ulama yang ada di daerah tersebut dan tetua-tetua yang memiliki pengaruh di masyarakat." (Wawancara, 23 Maret 2018)

Makna luhur dari budaya penggunaan batee ranup ini tidak mampu bertahan di tengah pesatnya laju zaman yang menawarkan budaya baru yang lebih sesuai dengan kehidupan masyarakat sekarang yang makin modern. Pada akhirnya budaya ini hanya sebatas diingat tanpa mampu dipertahankan. Meskipun begitu ada nasehat orang zaman dulu yang masih diingat oleh generasi sekarang perihal batee ranup ini, hal ini seperti yang diungkapkan oleh Ketua MAA Aceh Barat

"Orang dulu sering bilang mulia wareh ranup lampuan mulia rakan mameh suara (Saudara dan kerabat dimuliakan dengan sirih dalam puan sedangkan sahabat dimuliakan dengan tutur kata yang baik), anak-anak sekarang masih ada yang tahu nasehat ini meskipun mereka tidak mengerti makna dibalik nasehat tersebut. Adanya nasehat seperti ini menunjukkan bahwa batee ranup adalah bagian penting dari budaya kita." (Wawancara, 22 Maret 2018)

\section{Faktor yang Mempengaruhi Pergeseran Budaya Penggunaan Batee Ranup dalam Tradisi Meu- uroh}

Pergeseran budaya dalam masyarakat terjadi seiring pengaruh dari globalisasi dan masuknya budaya lain. Perkembangan teknologi berupa hadirnya internet dan informasi elektronik, ditemui dalam kenyataan sering sangat berbeda dari sistem nilai dan budaya. Perkembangan ini sangat cepat menghampiri generasi muda yang cenderung mudah dipengaruhi oleh elemen-elemen baru yang merangsang. Hal ini akan cepat membawa perubahan jika tidak disikapi dengan kearifan dan kesadaran akan makna dari budaya asli yang dianut. Dunia seakan tanpa batas dan transparan serta hubungan yang jauh menjadi sangat mudah dan dekat. Perubahan yang mendunia ini akan menyebabkan pergeseran nilai-nilai budaya tersebut. Hal tersebut selaras dengan pemaparan Ketua MAA Aceh Barat,

"Semenjak teknologi berkembang dengan pesat dan masuk sampai ke aceh, banyak hal yang berubah dalam kehidupan kita. Kita jadi bisa berkomunikasi saling bertatap muka karena ada hp model sekarang yang canggih. Yang jauh jadi terasa dekat. Jika untuk hal-hal yang baik dan bermanfaat seperti contoh hp tadi, kita boleh menggunakan dan beralih ke teknologi.Tapi, kalau teknologi sampai membuat kita membuang jati diri kita sendiri, kan itu 
sudah diluar kewajaran. Kita lahir dan dibesarkan dalam tradisi ini, kenapa kita harus buang tradisi ini hanya karena tidak mau disebut ketinggalan zaman." (Wawancara, 22 Maret 2018)

Penggunaan batee ranup dalam tradisi meu-uroh memiliki nilai yang luhur yakni bermakna kemuliaan atau simbol penghormatan dari orang yang melakukan meu-uroh kepada orang yang hendak diundang ke hajatan yang akan digelar. Namun, makna dan nilai luhur ini tidak mampu bertahan oleh terpaan arus teknologi yang menawarkan cara meu-uroh model baru yang lebih efisien dalam hal pengunaan waktu dan uang meskipun tidak seratus persen efektif dalam hal penerimaan oleh orang yang hendak diundang. Hal ini dikarenakan inovasi mengundang dengan cara ini belum diterima oleh seluruh lapisan masyarakat.

Budaya yang merupakan warisan nenek moyang yang telah diwariskan dari generasi ke generasi tentu memiliki tempat tersendiri di hati dan hidup masyarakat. Ketika budaya tersebut mengalami pergeseran atau bahkan menghilang sama sekali, tentu ada banyak faktor yang menjadi penyebabnya. Budaya penggunaan batee ranup dalam tradisi meu-uroh ini sudah jelas memiliki makna yang luhur dan keluhuran ini masih membekas di hati sebagian masyarakat yang paham dan mengerti akan budaya asli mereka. Namun, ketika budaya ini hilang tentu ada hal-hal yang menjadi pendorong terjadinya hal tersebut. Seperti yang disampaikan oleh Ketua MAA Aceh Barat Tjut Agam kepada Peneliti,

"Budaya kita perlahan-lahan hilang karena budaya luhur kita ini tidak berakar dengan baik dalam diri masyarakat sekarang. Penyebabnya bisa karena tidak adanya penanaman pemahaman dalam diri masyarakat usia muda oleh masyarakat usia tua yang lebih paham tentang makna dan pentingnya budaya tersebut. Sehingga ketika ada budaya lain atau budaya asing masuk maka masyarakat dengan sedikit pemahaman ini akan cenderung ikutikutan dan terpengaruh, yang pada akhirnya menggunakan budaya baru tersebut sebagai bagian dari identitas diri mereka. Agar budaya luhur kita tidak hilang sepenuhnya, masyarakat harus punya kesadaran untuk melestarikan dan mengedukasi generasi muda tentang budaya-budaya asli aceh sebagai bagian dari identitas keacehan kita." (Wawancara, 22 Maret 2018)

Selain itu, dalam hal hilangnya minat masyarakat untuk menggunakan batee ranup ini ketika meu-uroh juga disebabkan oleh hadirnya macam-macam teknologi dan budaya baru yang lebih sesuai dengan perkembangan zaman. Meu-uroh dengan batee ranup terlihat menjadi sangat kuno dan ketinggalan zaman jika disandingkan dengan budaya baru yang masyarakat lihat dan dapati di luar sana. Hal ini disampaikan oleh Ketua MAA Aceh Barat,

"Kehadiran teknologi membawa perubahan yang besar. Kehadiran mesin-mesin canggih di tengah masyarakat membuat sistem kehidupan yang tadinya tradisional menjadi berubah. Seperti hadirnya televisi yang membuat masyarakat dapat melihat dunia luar. Banyak hal dari budaya luar yang akhirnya ditiru oleh masyarakat seperti cara berpakaian yang tadinya santun menjadi kebarat-baratan. Masyarakat juga jadi lupa dan acuh dengan budaya sendiri ketika melihat ada budaya lain yang menurut mereka lebih kekinian dan mudah dilakukan. Seperti cara mengundang ini, awalnya masyarakat hanya melihat dan merasa tertarik tetapi akhirnya menjadi benar-benar diterapkan ketika mesin cetak juga masuk ke masyarakat." (Wawancara, 22 Maret 2018) 
Tidak hanya soal selera dan keinginan untuk menjadi sama dengan orang lain di luar sana, kenyataan yang menunjukkan bahwa teknologi mampu memberikan sarana menjalankan tradisi ini dengan budget yang lebih minim juga menjadi pertimbangan masyarakat. Hal ini didukung pula oleh kepraktisan yang ditawarkan oleh budaya baru tersebut, dimana waktu yang diperlukan untuk meuuroh dengan undangan cetak jauh lebih singkat jika dibandingkan dengan meu-uroh menggunakan batee ranup.

Hal ini senada dengan yang disampaikan oleh Keuchik Desa Cot Lagan,

"Uroe jeh jak meu-uroh rap sibuleun peunoh, bahkan na yang leubeh sibuleun nyoe kanuri rayeuk. Menyoe jinoe siminggu kalheuh. Jadi ureueng poe rumoh hana trep cantoi keurija, maken trep meutemei keurija peng untuk kanuri koen jadi leubeuh le. Loem pih dilei mantong mudah meu-uroh ba batee ranup karena rap tip rumoeh na bak ranup droe jadi hanya payah blau. Nyoe jinoe ureueng galak meu-uroh ngon kertah undangan karena leubeuh murah daripada ta blau ranup.

Dulu orang meu-uroh hampir sebulan penuh bahkan ada yang lebih dari sebulan bagi yang pestanya lebih mewah. Hal ini tentu berbeda dengan sekarang yang hanya butuh waktu seminggu untuk melakukannya. Sehingga orang yang bersangkutan tidak perlu meninggalkan pekerjaannya terlalu lama, dengan begitu mereka jadi memiliki lebih banyak uang untuk keperluan hajatan. Selain itu, keadaan dulu masih mendukung untuk meu-uroh dengan membawa sirih karena dulu hampir setiap rumah memiliki tanaman ini sehingga tidak perlu mengeluarkan uang untuk mendapatkannya. Sementara untuk sekarang, meu-uroh dengan undangan kertas atau sekapur sirih dirasa lebih murah dibandingkan dengan membeli sirih." (Wawancara, 23 Maret 2018)

Selain itu, beliau juga menambahkan

"Nyoe jak meu-uroh jih jioh susah cit ba batee ranup, karna nyoe sampoe on ranup nyan thoh bak roet gob koen haek dipajoeh le cit. Jika meu-uroh ke tempat yang jauh susah juga bawa batee ranup karena kalau sampai daun sirihnya kering orang juga tidak akan mau memakannya." (Wawancara, 23 Maret 2018)

\section{Pro Kontra Penggunaan Undangan Cetak}

Seiring dengan pesatnya perkembangan zaman, tentu ada masyarakat yang tetap bertahan dengan segala macam tradisi yang telah lama dianutnya dan ada juga masyarakat yang menerima perubahan dalam hal kebudayaan ini sehingga meninggalkan budaya asli dimana masyarakat itu berasal. Terlepas dari baik buruknya nilai dan makna dari suatu budaya asli, masyarakat tentu memiliki pandangan dan alasan tersendiri ketika memilih menggunakan budaya baru atau tetap bertahan pada budaya lama.

Hal tersebut berlaku pada penggunaan batee ranup dalam tradisi meu-uroh yang mengalami pro dan kontra dalam mempertahankan budaya tersebut atau beralih menggunakan undangan cetak "sekapur sirih". Sebagian besar masyarakat lebih senang menggunakan undangan cetak, hal ini senada dengan yang diungkapkan oleh Erna Farida salah satu masyarakat desa cot lagan, 
"Lam thoen nyoe kamoe ka dua goe peugot kanuri dan ban dua goe nyan pakek undangan sekapur sirih. Pakek undangan lage nyoe leubeh mudah dan leubeh murah. pue loem kamoe na alat cetak droe jadi cuma peurele blau keretah ngon tinta jieh mantong. Menyoe meu-uroh ngoen batee ranup payah bacut dan leubeuh meuhai', karna jinoe oen ranup payah blau cit dan yum jieh leubeh meuhai' nyoe dibandingkan cetak undangan keudroe.

Dalam tahun ini kami sudah mengadakan dua kali pesta dan dua-duanya menggunakan undangan kertas atau sekapur sirih. Menggunakan undangan seperti ini lebih mudah dan lebih murah juga. Apalagi kami punya alat cetak undangan sendiri jadi kami hanya perlu membeli kertas sama tintanya saja. Kalau meu-uroh dengan batee ranup agak sedikit merepotkan dan lebih mahal juga, karena sekarang daun sirih harus beli dan harganya lebih mahal jika dibandingkan cetak undangan sendiri." (Wawancara, 26 Maret 2018)

Begitu juga yang diungkapkan oleh Desi salah seorang informan di desa Cot Lagan:

"Jinoe ka leubeh mangat meu-uroh ngoen undangan keretah nyan karna proses jieh mudah dan hana trep cit watee tajak. Pue loem oen ranup jinoe that payah ta mita. Dilei rap tip rumoeh na bak ranup jadi hana payah blau watee meujak meu-uroh, nyoe jinoe dumpue payah blau dan yum jieh leubeh meuhei' nyoe ta bandeng ngon ta cetak undangan nyan.

Sekarang lebih mudah meu-uroh dengan kertas undangan karena prosesnya mudah dan tidak butuh waktu lama. Apalagi sekarang daun sirih tidak mudah didapat seperti dulu. Dulu hampir setiap rumah ada tanaman sirihnya jadi tidak perlu beli ketika meu-uroh, tapi sekarang daun sirih harus beli dan biayanya akan lebih besar daripada membuat undangan berbentuk kertas seperti sekarang." (Wawancara, 26 Maret 2018)

Setiap perubahan pasti memiliki dampak yang berbeda-beda pada setiap orang. Meskipun ada yang menerima dengan alasan bahwa budaya yang ada sekarang lebih baik dan sesuai dengan kebutuhan mereka, namun ada juga masyarakat yang masih setia bertahan dengan budaya lama dengan alasan keluhuran yang dimiliki oleh budaya tersebut.

Hal ini sesuai dengan yang diungkapkan oleh M.Amin, salah satu informan yang menolak adanya perubahan dalam tradisi meu-uroh, beliau menuturkan

"Meu-uroh jinoe that jioh beda dengon meu-uroh jamen dilei. Jinoe ureueng-ureueng yang jak meu-uroh le that yang Cuma dititep undangan nyan bak gob atau menyoe yang meu-uroh nyan ureueng gampong Cuma diyak peugah sampai pinto rumoh mantong, meudi tamoeng pieh han beek ta peugah di duk meuberakah. Nyoe cara jieh meunan loen keudroe hana le akeumak dak hana loen jak. Ureueng poe kanuri mantong han troh ijak bak tanyoe jak intat undangan nyan, jadi keupue loen yak jak. Ban nyoe lhe oen undangan yang loen priek. Ka lagei hana yum le tanyoe nyoe. Nyoe dilei senang ate-ate wateee na ureueng jak meu-uroh, pue loem nyoe yang ba ranup bentuk kupiah teuku uma nyan. Sang dak hana peng meu-utang pieh jeut untuk jak bak kanuri nyan.

Meu-uroh sekarang sudah sangat jauh berbeda dengan meu-uroh masyarakat dulu. Sekarang orang yang meu-uroh kebanyakan hanya menitipkan undangan pada seseorang untuk disampaikan kesini atau jika yang meu-uroh itu orang satu desa mereka hanya menyampaikan undangan secara lisan di depan pintu, jangankan untuk berbincang-bincang untuk duduk saja mereka tidak bersedia. Dengan cara yang seperti itu saya sendiri merasa jadi tidak punya alasan untuk datang ke hajatan tersebut. Orang yang punya hajatan saja tidak berkenan datang kesini untuk langsung menyampaikan undangan ini, jadi buat apa saya datang ke undangan tersebut. Baru-baru ini saja ada tiga kertas undangan yang langsung 
saya robek ketika baru sampai. Kita merasa seperti sudah tidah dihormati lagi. Kalau dulu, kita merasa senang ketika ada yang datang meu-uroh apalagi yang membawa sirih dengan bentuk kupiah teuku uma, sekalipun sedang tidak uang tetap akan saya usahakan untuk datang." (Wawancara, 26 Maret 2018)

Perasaan tidak senang ketika menerima undangan cetak dari orang lain menjadi salah satu alasan bagi sebagian masyarakat untuk mempertahankan cara mengundang dengan batee ranup. Hal ini senada dengan yang diungkapkan M.Amin,

"Watee aneuk-aneuk loen na peugot kanuri dan neuk jak meu-uroh sabe loen peugah untuk tetap ba batee ranup walaupun na yang kalheuh cetak undangan. Loen ka rasa hana mangat nyoe cuma dikirem undangan, jadi gob pasti dirasa hana mangat cit. Nyoe ta undang ureueng tuha sang tan meu sopan le pih nyoe cuma ta kirem undangan lagei yang ureueng jinoe pubut.

Saat anak saya mau melaksanakan hajatan dan hendak meu-uroh saya selalu bilang untuk tetap membawa batee ranup walaupun ada yang sudah cetak undangan. Saya sudah merasakan betapa tidak enaknya jika orang cuma mengirimkan undangan, jadi orang lain pasti merasakan hal yang sama. Jika mengundang orang tua rasanya tidak sopan kalau cuma mengirimkan undangan seperti yang orang sekarang lakukan." (Wawancara, 26 Maret 2018)

Hal serupa juga diungkapkan oleh Mameh salah seorang masyarakat Desa Cot Lagan,

"Jinoe undangan ka le dititep bak gob. Ngon alasan nyoe jeh pokok jieh u rumoeh tanyoe han troeh dijak. Ladoem meu dituri tanyoe pieh tan. Jieh cuma sekedar ditupue mantong na syedara ngon tanyoe. Kadong tanyoe cit Cuma sepupu tu jieh, jadi karna han toem jak meujak dan watee na acara meu-uroh meunoe pieh hana troeh dijak u rumoeh, watee tanyoe troh bak kanuri nyan pieh hana soe meupremeun, hai hana dituri. Karna na yang lage-lage nyoe keuh loen jadi kureung galak meu-uroh ngon cara jinoe. Pue loem oh lheuh abeh peng untuk ta ba kado, kadong ureueng rumoh hana meuthat diharap tanyoe jak keunan.

Sekarang undangan kebanyakan dititipkan sama orang lain. Dengan berbagai alasan orangorang yang melaksanakan hajatan ini sudah kurang ada yang mau datang langsung ke rumah. Si empunya hajatan hanya sebatas tahu kalau keluarganya masih punya ikatan saudara dengan kita. Bisa saja kita ini adalah sepupu dari kakek yang punya hajatan, jadi karena tidak saling mengunjungi dan meu-uroh tanpa langsung ke rumah, ketika kita datang ke hajatan itu pun orang yang punya hajatan tidak akan menggubris kita karena tidak dia kenal. Dengan adanya kasus-kasus seperti ini, saya jadi kurang suka dengan cara orangorang sekarang meu-uroh karena setelah habis uang untuk hadiah ke hajatan itu, orang yang punya hajatan belum tentu menganggap penting kehadiran kita." (Wawancara, 25 Maret 2018)

Hal berbeda diungkapkan oleh Cut Ti Hawa salah seorang informan di desa cot lagan, Beliau menuturkan

"Jinoe jameun ka meu-ubah, dilei ureueng pakek batee ranup karna mandum cit pakek nyan. Tapi karna jinoe kana yang leubeh mudah, yaa tanyoe ta pakek yang na jinoe nyan cit. Pue loem bak undangan keretah nyan ka dituleh tangga-tangga jadi tanyoe han tuwoe. Menyoe ba batee ranup tok cit uroe nyan dak na teuingat, lheuh nyan karna but nyoe dan but jeh tanyoe pasti tuwoe pajan kanuri nyan.

Sekarang zaman sudah berubah, dulu orang memakai batee ranup karena memang semua menggunakan itu. Tetapi karena sekarang sudah ada yang lebih mudah dan praktis, ya kita pakai yang ada sekarang. Apalagi undangan kertas ini di dalamnya sudah tercantum tanggal acara jadi kita tidak akan lupa. Kalau bawa batee ranup orang hanya akan ingat sampai hari 
orang itu datang saja setelah itu karena banyak kesibukan kita pasti akan lupa tentang tanggal acara atau bahkan dengan acara sekalipun." (Wawancara, 26 Maret 2018)

Perbedaan pandangan dari generasi tua Cut Ti Hawa ini dengan generasi-generasi tua lainnya terjadi karena beliau pernah lama menetap di Jakarta dengan anaknya. Hal tersebut sedikit banyak mempengaruhi cara pandang beliau akan budaya yang ada di Cot Lagan. Beliau menuturkan

"Di Jakarta ureueng peugot pesta hana sibuk lagei tanyoe nyoe cuma masalah undangan. Lheuh dicetak cuma perele jok bak kantor pos untuk disebar menurot alamat yang tanyoe tuleh. Setidak jieh tanyoe na kemajuan nyoe ka mulai pakek undangan cetak.

Di Jakarta orang yang buat pesta tidak sibuk seperti kita kalau Cuma masalah undangan. Setelah undangan siap dicetak Cuma perlu dibawa ke kantor pos untuk disebar ke alamat yang sudah kita cantumkan diundangan tersebut. Setidaknya kita sudah ada kemajuan ketika memulai menggunakan undangan cetak ini”. (Wawancara, 26 Maret 2018)

Mengenai awal mula masyarakat desa Cot Lagan beralih menggunakan undangan cetak, Keuchik Desa Cot Lagan menuturkan

"Hai phoen-phoen meu-uroh pakek undangan keretah nyoe dipakek lek ureueng-ureueng kaya lage keluarga awak nyak ngon teuku. Karna dilei undangan nyoe mantong meuhai untuk ureueng gampong biasa. Pue loem dilei mesen cetak cuma na di meulaboh dan oen ranup pieh mantong le wate nyan. Nyoe jinoe oen ranup hana le dan harus blau, hana le oen ranup nyoe langsong digantoe dengon ditamong mesen cetak.

Awalnya model meu-uroh ini dipakai oleh orang-orang kaya seperti keluarga Nyak dan Teuku. Karena dulu undangan cetak ini masih bisa dibilang mahal untuk kita orang kampung. Apalagi dulu mesin cetak cuma ada di Meulaboh dan daun sirih pada saat itu juga masih banyak. Sementara sekarang daun sirih sudah tidak ada dan harus beli, kekosongan ini diisi dengan masuknya mesin cetak sehingga pada akhirnya mengubah suatu budaya". (Wawancara, 23 Maret 2018)

Mengedukasi generasi muda tentang budaya asli masyarakat adalah tugas kita semua terutama generasi tua yang memiliki pemahaman lebih akan pentingnya budaya tersebut. Kini generasi tua hanya bisa menyayangkan tentang pergeseran budaya ini tanpa bisa membendung arus yang akan membawa dan menghilangkan nilai-nilai luhur dari budaya asli kita. Meskipun begitu, para generasi tua setidaknya memaklumi tentang kecenderungan generasi muda dalam menyukai hal-hal praktis dan instan. Hal ini sesuai dengan yang diungkapkan oleh M.Jakfar, salah seorang masyarakat yang dituakan di Desa Cot lagan,

"Aneuk-aneuk jinoe cit ka udep lam mudah dengon na mesen-mesen yang peumudah but siuroe-uroe. Aneuk jinoe pat ditem timok ie wate jeut ditemei ie ngon puta kran. Pat item peh capli nyoe watee kana blender. Jadi ka maklum nyoe aneuk-aneuk jinoe han le sanggop peuturot adat lagai ureueng jamen. Pat ditem meu-urusan ngon gapue pineng watee na cara laen lagai pakek keretah jinoe".

Anak-anak sekarang hidup didampingi oleh mesin-mesin yang memudahkan pekerjaan sehari-hari mereka. Mereka tidak akan mau menimba air ketika bisa mendapatkan air dengan memutar keran. Mereka bisa menganggap mengulek sambal itu merepotkan ketika sudah ada blender. Jadi sudah bisa dimaklumi jika anak-anak sekarang tidak akan sanggup menjalankan tradisi seperti orang-orang dulu. Mereka tidak akan mau berurusan dengan kapur dan pinang ketika bisa hanya menggunakan kertas. (Wawancara, 26 Maret 2018) 
Selain itu, beliau juga menambahkan

"Hai hana mandum cit ikoet-ikoet lagei nyang na jinoe. Aneuk teungku pakeh that haye-haye tapi mantong dipakek batee ranup watee jak meu-uroh keunoe. Nyan mungken karna dikaloen ureueng chiek awaknyan dipubut meunan. Aneuk koen ikoet kiban ureueng tuha. Hai nyoe nyang tuha ka meulaen, aneuk pu loem ta peugah.

Tapi tidak semua juga jadi ikut-ikutan seperti yang ada sekarang. Anak tgk pakeh sangat pintar dan kaya-kaya tapi masih menggunakan batee ranup ketika melakukan tradisi meuuroh. Itu mungkin karena mereka melihat orang tuanya melakukan seperti itu. Anak kan ikut seperti orang tua. Ya kalau orang tuanya berubah, anaknya apalagi" (Wawancara, 24 Mei 2018)

Pengaruh teknologi maupun pengaruh dari luar lainnya seyogyanya dapat dibendung jika dalam setiap keluarga ada yang menanamkan pemahaman dan kecintaan akan budaya dan tradisi yang ada. Proses penanaman pemahaman ini tidak selalu berupa proses belajar secara langsung namun dapat dilakukan dengan mempraktekkannya sehingga akan dilihat dan akhirnya diikuti oleh semua orang yang ada di keluarga tersebut.

\section{E. PEMBAHASAN}

Penyebab Terjadinya Pergeseran Budaya Penggunaan Batee Ranup dalam Tradisi Meu-uroh di Desa Cot Lagan Kecamatan Woyla Kabupaten Aceh Barat

Seiring dengan perkembangan teknologi dan munculnya modernisasi sangat banyak budaya yang tradisional hilang oleh hadirnya budaya baru yang terus berdatangan tanpa bisa dibendung. Arus ini datang dari segala arah dan menghampiri hampir semua segi kehidupan manusia. Hal tersebut menuntut manusia untuk berpikir dan menentukan sikapnya dalam menerima atau menolak budaya baru.

Budaya baru yang masuk dan berkembang di tengah-tengah masyarakat bermacam-macam baik dalam bentuk teknologi material maupun budaya. Hal tersebut hadir di tengah-tengah masyarakat dan seakan membius untuk terus mengikuti budaya baru tersebut. Sangat rugi bagi masyarakat aceh yang terkenal dengan kekayaan budayanya jika sampai terpengaruh dan akhirnya meninggalkan budaya sendiri yang penuh dengan keluhuran untuk mengikuti budaya luar yang tidak jelas asal usulnya.

Budaya asli masyarakat Desa Cot Lagan berupa kegiatan meu-uroh dengan membawa batee ranup kini sudah mulai ditinggalkan. Pergeseran yang terjadi ini disebabkan oleh beberapa faktor yang secara langsung maupun tidak telah mempengaruhi cara pandang masyarakat tentang budaya itu sendiri. Adapun faktor-faktor tersebut adalah:

\section{Transformasi Budaya}

Suatu budaya akan mudah hilang dan tergantikan jika budaya itu tidak benar-benar dipahami oleh masyarakat. Kenyataan bahwa makna dari suatu budaya tidak berakar dengan baik di hati masyarakat menjadi faktor mendasar yang pada akhirnya membuat masyarakat dengan cepat 
menerima budaya baru yang masuk dan berkembang dalam kehidupan mereka. Menjaga dan melestarikan budaya adalah tugas dari semua orang disetiap generasi. Oleh karena itu, para generasi tua dituntut untuk mau berpartisipasi dalam hal menanamkan pemahaman pada generasi muda tentang budaya yang menjadi warisan nenek moyang kita.

Pemahaman yang baik akan menumbuhkan kecintaan akan budaya itu sendiri. Ketika rasa cinta akan budaya itu dimiliki oleh semua orang maka ketika budaya baru masuk masyarakat akan lebih membentengi diri dan mampu menfilter hal-hal tersebut sebelum memutuskan untuk mengadopsi atau menolak sama sekali.

Pentingnya penanaman pemahaman ini secara nyata terlihat dari masih adanya kelompok generasi muda yang melestarikan dan menjalankan tradisi ini. Hal yang melatar belakangi keputusan mereka untuk setia pada budaya asli yang ada adalah tindakan sehari-hari orang tua atau keluarga terdekat mereka yang masih memegang teguh tradisi tersebut..

\section{Teknologi}

Kebudayaan adalah suatu sistem yang senantiasa berubah dan selalu berusaha menyesuaikan diri dengan perkembangan zaman. Pesatnya perkembangan teknologi yang melanda dan masuk ke kehidupan masyarakat membawa banyak pengaruh dan perubahan. Hadirnya alat-alat teknologi canggih sedikit banyak telah mampu membuat cara hidup masyarakat yang tadinya tradisional menjadi lebih modern.

Dalam budaya penggunaan batee ranup ketika melaksanakan tradisi meu-uroh telah terjadi perubahan seiring dengan masuknya alat-alat teknologi ke masyarakat. Perubahan ini dianggap sebagai suatu inovasi baru yang dalam penerapannya membawa banyak keuntungan bagi orang yang melaksanakan tradisi meu-uroh ini.

Dalam teori difusi inovasi, ada konsep keuntungan relatif yang menjadi pertimbangan adopter dalam mengadopsi atau menolak suatu inovasi. Semakin besar keuntungan relatif yang dirasakan oleh adopter, maka akan menjadikan suatu inovasi semakin cepat proses pengadopsiannya oleh suatu kelompok.

\section{Ekonomi}

Masyarakat sekarang menghubungkan hampir seluruh hal dalam kehidupannya dengan ekonomi atau uang. Meu-uroh awalnya adalah salah satu cara yang dilakukan untuk menyambung silaturrahmi atau mempererat persaudaraan, hal ini didukung dengan penggunaan batee ranup yang memiliki makna yang mengena di hati masyarakat. Namun sekarang masyarakat sudah kurang memperhatikan makna atau tanggapan dari orang yang hendak diundang. Masyarakat hanya menjalankan tradisi ini sebagai salah satu syarat sebelum melakukan hajatan.

Masyarakat merasakan mudahnya melakukan tradisi meu-uroh dengan undangan cetak atau sekapur sirih. Hal ini juga dikarenakan modal untuk undangan cetak lebih murah dan bisa diprediksi daripada membeli sirih yang akan memakan modal yang lebih besar. 
Adanya keuntungan baik dalam hal ekonomi maupun dari segi kepraktisannya ini membuat inovasi penggunaan undangan cetak ini lebih mudah diterima dan diadopsi oleh masyarakat. Hal ini sesuai dengan karakteristik dari difusi inovasi itu sendiri dimana suatu inovasi akan lebih cepat proses pengadopsiannya apabila membawa banyak keuntungan dan dirasa masyarakat lebih baik dari budaya atau inovasi dalam tradisi sebelumnya.

Selain itu, inovasi yang ada juga sesuai dengan kondisi dan kebutuhan masyarakat sekarang. Budaya membawa sirih ketika meu-uroh hanya dirasa cocok dengan kondisi masyarakat dulu dimana mereka bisa mendapatkan sirih tersebut dengan cuma-cuma atau tanpa perlu mengeluarkan uang karena hampir setiap rumah menanamnya sendiri. Sementara sekarang sirih harus dibeli dengan harga yang lumayan mahal jika dibandingkan mencetak undangan.

\section{F. PENUTUP}

Batee ranup ini memiliki makna yang luhur yaitu kemuliaan bagi orang yang hendak diundang. Namun, tradisi yang memiliki makna luhur ini sudah jarang digunakan oleh masyarakat desa Cot Lagan. Adapun penyebab yang mendorong terjadinya pergeseran budaya penggunaan batee ranup dalam tradisi meu-uroh adalah sebagai berikut :

a. Transformasi Budaya

Pemahaman tentang budaya tidak berakar dengan baik dalam diri masyarakat. Penyebabnya bisa karena tidak adanya penanaman pemahaman tentang budaya itu sendiri. Hal ini mendorong pergeseran budaya, padahal jika pemahaman akan budaya itu dapat diwariskan maka budaya kita akan terus lestari.

b. Teknologi

Masuknya teknologi adalah salah satu faktor pendorong cepatnya terjadi pergeseran budaya dalam masyarakat. Hadirnya mesin-mesin yang mendukung terciptanya perubahan membuat masyarakat seakan tidak memiliki pilihan selain mengikuti dan menggunakannya.

c. Faktor Ekonomi Inovasi menggunakan undangan cetak dirasa oleh sebagian masyarakat lebih menguntungkan dalam hal penggunaan waktu dan uang. Hal ini karena undangan cetak lebih murah dan lebih praktis jika dibandingkan dengan membeli dan membawa sirih ketika melaksanakan tradisi meu-uroh.

\section{DAFTAR PUSTAKA}

Dadek, Teuku dkk. 2014. Kemana, Apa, Siapa di Aceh Barat. Aceh Barat: Aceh Printers.

Nuruddin. 2007. Pengantar Komunikasi Massa. Jakarta: Raja Grafindo Persada.

Puteh, M Jakfar. 2012. Sistem Sosial Budaya dan Adat Masyarakat Aceh. Banda Aceh: Grafindo Litera Media. 
Sanderson, Stephen K. 2011. Makrososiologi: Sebuah Pendekatan Terhadap Realitas Sosiologi. Jakarta: Rajawali Pers.

Sobur, Alex. 2009. Semiotika Komunikasi. Bandung: Remaja Rosdakarya.

Soekanto, Soerjono. 2007. Sosiologi Suatu Pengantar. Jakarta : Raja Grafindo Persada.

Sugiyono. 2009. Memahami Penelitian Kualitatif. Bandung : Alfabeta.

Prastyanti, Shinta. 2013. Difusi Inovasi dalam Konteks Pemberdayaan Masyarakat. Acta Diurna. Vol IX (1): 59-60. komunikasi.unsoed.ac.id. Diakses tanggal 10 Juli 2018 pukul 11:00. 